Wondimu, S.T., \& Birru, M.W. (2020). Determinants of Informal Economy Estimation in Ethiopia: Multiple-Indicators, Multiple-Causes (MIMIC) Approach. Copernican Journal of Finance \& Accounting, 9(2), 65-86. http://dx.doi.org/10.12775/CJFA.2020.008

\author{
Sintayehu Tulu Wondimu* \\ Jimma University
}

\author{
Mathewos Woldemariam Birru** \\ Wolaita Sodo University
}

\title{
DETERMINANTS OF INFORMAL ECONOMY ESTIMATION IN ETHIOPIA: MULTIPLE-INDICATORS, MULTIPLE-CAUSES (MIMIC) APPROACH
}

Keywords: informal economy, taxes burden, institutional quality, MIMIC model, Ethiopia.

J E L Classification: C12, C13, C31, M40.

Abstract: This paper explored the determinants of the informal economy size estimations with survey data in the multiple indicators, multiple causes (MIMIC) model. This model enables us to estimate the unknown variable with the known observable variables. The size of the informal economy estimated with observable variables and to conduct the estimation with this model grouped the observable variables of the study as causes and indicators. In the underlying study, the size of informal economy estimations the variables such as harmfulness of shadow economy, growth of money outside

Date of submission: March 11, 2020; date of acceptance: May 5, 2020.

* Contact information: sentyes@gmail.com, Department of Accounting and Finance, College of Business and Economics, Jimma University, Oromia Region, Ethiopia, phone: +251913271766; ORCID ID: https://orcid.org/0000-0002-2100-0283.

${ }^{* *}$ Contact information: mathewoswmariam@yahoo.com, Department of Accounting and Finance, College of Business and Economics, Wolaita Sodo University, SNNP Region, Ethiopia, phone: +235934104164; ORCID ID: https://orcid.org/0000-0003-04581212. 
banks, taxes burden, the intensity of government regulations, self-employment, unemployment rate, and agricultural sector dominance have the positive effects whereas the real GDP per capita, total employment, institutional quality, and tax morality have negative effects in the estimation of the informal economy size. The study recommended a future line of studies for scholars to undertake the study on the size of the informal economy estimations with the indirect approach using panel data to know the impacts on the regular economy and other related consequences on the economy.

\section{INTRODUCTION}

In empirical research, the size and development of the shadow economy show that grown rapidly all over the world. Nowadays the characterization of the informal economy has been debatable in the policy and academic circles. Presently no unique definitions for the term of the informal economy although express relation to the shadow, black, underground, illegal, hidden, unrecorded, and unreported economy. In this study to avoid, the controversial issues on terminologies use informal economy, shadow economy, informal work, informal sector, and informal economic activities interchangeably. Scholars availed equivalent terms for the informal economy as the irregular economy (Ferman \& Ferman, 1973), subterranean economy (Gutmann, 1977), underground economy (McCrohan, Smith \& Adams, 1991), black economy (Dilnot \& Morris, 1981), shadow economy (Frey, Weck \& Pommerehne, 1982; Cassel \& Cichy, 1986), and informal economy (McCrohan \& Smith, 1987). Also, express the informal economy with invisible, hidden, submerged, shadow, irregular, non-official, unrecorded, or clandestine terms (Schneider, 2003).

Most of the time the scholars preferred opens rather than concrete and closed definitions of an informal economy to addresses the three reasons. Firstly, a singular and arbitrary definition could leave out many characteristics and not reflex the current phenomenology, secondly, a precise definition could end up with inadequate mechanisms of measurement, and thirdly, different countries have informal economies with different characteristics (Eilat \& Zinnes, 2000). This situation avoids the misinterpretations and concept of the informal economy with the geographical gaps as well as location barriers.

Under the (Feige, 2016) study the informal economy comprises economic activities that avoid costs of doing the business and excludes from benefits and rights incorporated in the laws and administrative rules of the property right, commercial licensing, labor contracts, torts, financial credit, and social systems. Informal economy defined as a set of economic activities that takes place 
outside the framework of bureaucratic approaches of public and private sector business establishments (Trebicka, 2014). Although Trebicka (2014), describes the informal economy as a sector that produces legal goods, but does not comply with government regulations. These circumstances able the sector to expand and also the studies show that the size of the informal economy incremented from time to time in worldwide (Schneider \& Buehn, 2016). Nowadays the phenomenon increases the debates on the management of the informal economy. The business situations of the sector expressed with three contextual elements as informal employment; employment in the informal economy and all legal activities contribute to GDP, but not captured in the official statistics of the national accounts with the various reasons (Igudia, Ackrill, Coleman \& Dobson, 2016).

In various studies' attempts to estimate the sizes of the informal economy Schneider (2015), Schneider and Enste (2002), Williams and Schneider (2013), Alm, Martinez-Vazquez and Schneider (2004) and Feld and Schneider (2010), measures the size of informal economy while face the questions of how to express the informal business sectors. Scholars' undertaken contextual definitions to attempt for estimating the size of the informal economy. Pesut (1992) defined as part of the domestic product which is not measured under the official statistics of the national GDP accounts, whereas Schneider (2014), defined as market-based production of goods and services, whether legal or illegal, that escapes from the detection of the official estimates of the national GDP. In addition, the scholars' used the broadest definitions of the informal economy as economic activities and the income derived from them avoid government regulations, taxes, contributions, and likes. Even the present definitions of the informal economy lefts a lot of questions of the sectors to attempt for the estimation of the size of the informal economy. While to minimize the gaps uses the organizational level definitions of the informal economy to attempts for the estimations of the sizes of an informal economy; the informal economy includes the groups of activities most likely to be non-observed and expressed with the underground, illegal, informal sector to undertake in the households for the final uses (Leite \& Master, 2014).

In practice, the informal business sectors contribute to the overcoming of inefficient motivations on the regular economy. The informal economy has positive and negative effects on the particular country economy (Öğ̈nç \& Yllmaz, 2000). The positive effects of the informal economy bring the creation of job opportunities and improvement on social welfare whereas the negative ef- 
fects contribute to inefficient decisions for the policymakers. Rafael and Castro (2018), explores the positive effects of the shadow economy as a mechanism to avoid excessive regulations and allows the new entrant to join into the market and the negative effects, exposes the policymakers to made mistakes without recognizing the official accounts of nations and enforced to use inappropriate statistical data of the informal economy. While the international experience indicates that the share of the informal economy declines as the level of development increases, most economies in Sub-Saharan Africa and developing countries like Ethiopia holds a large informal sector for many years to come, with presenting both opportunities and challenges for policymakers (Sancak, Devine, Cangul, Wu, Liu, Nose \& Thomas, 2017). A growing informal economy places further pressure on the government to increase taxes which, in turn, encourages more economic agents in formalizing the business (Igudia et al., 2016). In contrary to the expectations, the evidence suggests that the size of the informal economy did not experience a significant reduction, despite a huge fall in the direct tax burden (Schneider \& Buehn, 2017). Knowingly the large informal economy reduces the state revenue and contributes to the inability to provide a large quantity and quality of public goods and sufficient regulations to addresses them (Schneider \& Enste, 2002).

Under the Schneider and Buehn (2017), study highlights and empirically tests the hypothesized determinants of the informal economy estimation and the variables includes the taxes burden, corruption, regulations, public sector policy, tax morale, deterrence, development of official economy, self-employment, unemployment and agricultural sectors dominances and also per the study of Andersen and Andersen (2019) distinguishes the determinant variables of the informal economy to estimate the size. In this study to meet the multiple indicators, multiple causes (MIMIC) model grouped the determinant variables of the study as causes and indicators.

While estimating the size of the informal economy is a difficult and challenging task due to the nature and economic activities of the business operations. Knowingly various methods are applicable for estimating the size of the informal economy. Although each method described with its strengths and weaknesses. In this study undertaken the estimation of the size of the informal economy with the MIMIC model with taking the comparative advantages of the MIMIC model with other methods (Schneider \& Buehn, 2017). 


\section{THE RESEARCH METHODOLOGY AND THE COURSE OF THE RESEARCH PROCESS}

This study developed mixed research methods to combine the qualitative and quantitative data to undertake the study on the determinants of the informal economy estimation in Ethiopia with the multiple indicators, multiple causes model.

\section{Sources of data, types of data and methods of data collection}

The primary data collected with designed survey instruments. The instruments consist of open and close-ended questions. Open-ended questions enable the respondents to write opinions without restrictions and also cover the ideas that might not be indicated on the instruments. Closed-ended questions designed with the five-point Likert scale measurements. The scales represented as (1) strongly disagree, (2) disagree, (3) neutral, (4) agree, and (5) strongly agree. Close-ended questions support to access a high degree of response rate from the expected sample respondents.

\section{Target population, sample size and sampling techniques}

Target population of the study taken from the informal business sectors of different state and city administrations of Ethiopia proportionately. In the study undertaken the sub-classifications of a sample to address the required analysis, variation, precision, availability, and cost of investigations (Singh \& Masuku, 2014). In the determination of sample size as well as to draw the appropriate sample size taken into accounts the level of precision, confidence, and degree of variability (Singh \& Masuku, 2014). The study use the equation to determine the sample size of the study in accordance to (Sison \& Glaz, 1995), developed the equation to yield a representative sample for proportions of a large sample of the study and presented the equation as follows:

$$
n=\frac{Z^{2} p q}{e^{2}}
$$

Where is sample size, $\mathrm{Z}^{2}$ is abscissa of normal curve cutoff an area $\alpha$ at the tails ( 1 - $\alpha$ equals desired confidence level is 95\%), $e$ is desired level of precision, $p$ is 
estimated proportion of attribute and q is 1-p. Per the above equation determined the sample size and proportional simple random sampling method was employed to select a sample from each state and city administration of the nation with taking into a stratum.

$$
n=\frac{(1.96)^{2}(0.5)(0.5)}{(0.05)^{2}}=384
$$

\section{Methods of data analysis}

After accomplishing data collections undertaken the descriptive and econometric data analysis with the aid of Statistical software. In parallel to the descriptive analysis conduct the econometric analysis with the statistical regression model known as multiple-causes, multiple-indicators (MIMICs) for the study.

\section{Model Specification: Multiple-Indicators, Multiple-Causes (MIMIC) model}

Multiple-Indicator, Multiple-Causes (MIMIC) model is a type of structural equation model, which is based on the statistical theory of the latent variables (Igudia et al., 2016). The concept of the MIMIC model is to examine the relationships between a latent variable known as the size of the informal economy and observable variables in terms of the relationships among several observable variables by using their information of covariance. The observable variables are grouped into indicators and causes of the size of the informal economy (Schneider \& Buehn, 2016).

The MIMIC approach allows the modeling of informal economy activities as a latent variable and considers its multiple effects (indicators) and determinants (causes). A factor-analytic approach is applied to measure the size of informal economy activities as an unobserved variable over time. Unknown coefficients are estimated in a set of structural equations, as the unobserved variable, meaning that the size of the informal economy cannot be measured directly (Schneider \& Buehn, 2016). This implies that the MIMIC model enables as to measure the unknown latent variable, that is, the sizes of an informal economy with taking the known variables as indictors and causes. 
A MIMIC model tries to estimate the size of the informal economy in the context of a flexible statistical model. This model expressed with two components of equations firstly, specifies the informal economy as a latent endogenous variable which is causally related to several factors and secondly, the informal economy determines a set of endogenous indicators. Identification in the model comes from restrictions on structural parameter values and the variance-covariance matrix of the error terms (Quintin, 2014). Under the Schneider and Buehn (2017) study the MIMIC estimation procedure described as the modeling of the shadow economy as latent, express the relation between the latent variable and its causes to develop the structural model and finally link between the latent variable and its indicator to develop the measurement model.

The MIMIC model explains the relationship between observable variables and an unobservable variable by minimizing the distance between the sample covariance matrix and the covariance matrix predicted by the model. Observable variables categorized into causes and indicators of the latent variable. The model consists of the structural equation model and the measurement model. The structural equation model is given by:

$$
\eta_{t}=\gamma^{\prime} x_{t}+\varsigma_{t}
$$

Where: Structural model determines the latent variable by a set of exogenous variables as causes of the latent variable. $x_{t}^{\prime}=\left(x_{1 t}, x_{2 t} \ldots x_{p t}\right)^{\prime}$ useful in predicting its movement and size, subject to a structural disturbance error term $S_{t} \cdot \gamma^{\prime}=\left(\gamma_{1}, \gamma_{2} \ldots . \gamma_{q}\right)$ a $(1 \times \mathrm{q})$ a $(1 \times q)$ vector of coefficients in the structural model describing the causal relationships between the latent variable and its causes. Since the structural equation model only partially explains the latent variable $\eta_{t}$, the error term represents the unexplained component. The model assumes that the variables are measured as deviations from their means and the error term does not correlate to the causes, i.e. $\sum\left(\eta_{t}\right)=\sum x_{t}=\sum \varsigma_{t}=0$ and $\sum x_{t} \varsigma^{\prime}{ }_{t}=\sum \varsigma_{t} x_{t}^{\prime}=0$.

The measurement model represents the link between the latent variable and its indicators, that is, the latent unobservable variable is expressed in terms of observable variables. It is specified by:

$$
\gamma_{t}=\lambda \eta_{t}+\varepsilon_{t}
$$


Where: Unobservable variable $\eta_{t}$ determines a $p$ vector $y_{t}^{\prime}=\left(y_{1 t}, y_{2 t} \ldots . y_{p t}\right)^{\prime}$ of indicators, that is, observable variables that reflect shadow economy activities, subject to a $p$ vector of random error terms $\varepsilon_{r t}=\left(\varepsilon_{1 t}, \varepsilon_{2 t} \ldots \ldots \varepsilon_{p t}\right)^{\prime}$. The unobservable variable $\eta_{t}$ is a scalar and is a $p$ column vector of parameters that relates $y_{t}$ to $\eta_{t}$. The indicators are directly measurable and expressed as deviations from their means, that is $\sum \gamma_{t}=\sum \varepsilon_{t}=0$. Moreover, it is assumed that the error terms in the measurement model do not correlate either to the causes $x_{t}$ or to the latent variable $\eta_{t}$, hence, $\sum x_{t} \varepsilon^{\prime}{ }_{t}=\sum \varepsilon_{t} x^{\prime}{ }_{t}=0$ and $\sum \eta_{t} \varepsilon^{\prime}{ }_{t}=\sum \varepsilon_{t} \eta^{\prime}{ }_{t}=0$. A final assumption is that the $\varepsilon_{t} \mathrm{~s}^{\prime}$ do not correlate to $S_{t}$, i.e. $\sum \varepsilon_{\mathrm{t}} \varsigma_{\mathrm{t}}^{\prime}=\sum \mathrm{S}_{\mathrm{t}} \varepsilon_{\mathrm{t}}^{\prime}=0$. The below figure presents the general structure of MIMIC model.

Figure 1. General Structure of a MIMIC Model

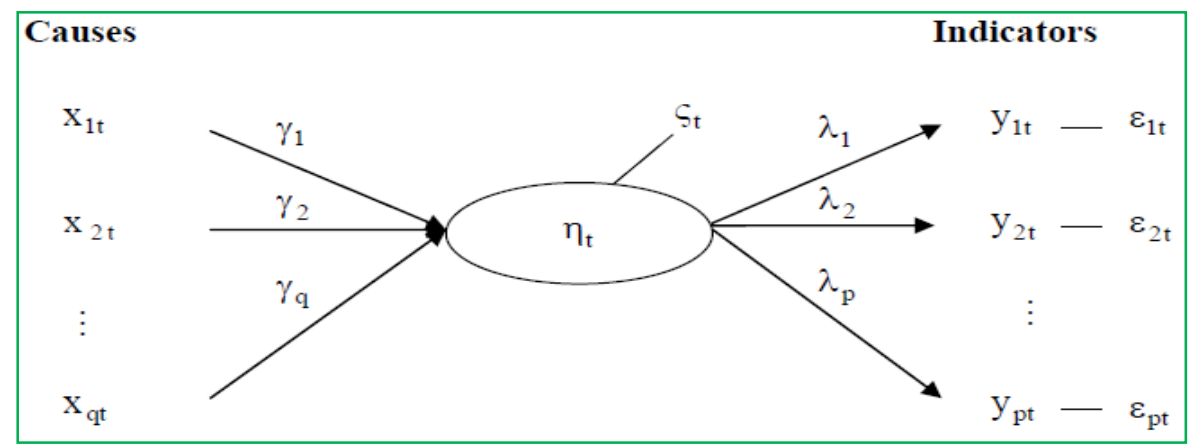

S o u r c e : adopted from Schneider and Buehn (2017).

Substituting (1) into (2) yields a reduced form equation which expresses the relationships between observed causes and indicators between $\boldsymbol{x}_{\boldsymbol{t}}$ and $\boldsymbol{y}_{\boldsymbol{t}}$. This is shown in equation:

$$
\gamma_{t}=\Pi \chi_{t}+z_{t}
$$

Where $\Pi=\lambda \gamma$ is a reduced form coefficient matrix and $z_{t}=\lambda \varsigma_{t}+\varepsilon_{t}$ is a reduced form vector of a linear transformation of disturbances that has a reduced form covariance matrix $\Omega$ given as:

$$
\Omega=\operatorname{cov}\left(z_{t}\right)=E\left[\left(\lambda \varsigma_{t}+\varepsilon_{t}\right)\left(\lambda \zeta_{t}+\varepsilon_{t}\right)^{\prime}\right]=\lambda \psi \lambda^{\prime}+\Theta \varepsilon
$$


In equation (4), $\left.\psi=\operatorname{Var}\left(\varsigma_{t}\right)\right)$ and $\Theta \varepsilon=E\left(\varepsilon_{t} \varepsilon_{t}^{\prime}\right)$ is the measurement error's covariance matrix.

In general, the estimation of a MIMIC model uses covariance information of sample data to derive estimates of population parameters. Instead of minimizing the distance between observed and predicted individual values, as in standard econometrics, the model minimizes the distance between an observed (sample) covariance matrix and the covariance matrix predicted by the model the researcher imposes on the data. The idea behind such an approach is that the covariance matrix of the observed variables is a function of a set of model parameters:

$$
\sum=\sum(\theta)
$$

Where $\Sigma$ is the population covariance matrix of the observed variables, $\theta$ is a vector that contains the parameters of the model and $\Sigma(\theta)$ is the covariance matrix as a function of $\boldsymbol{\theta}$, implying that each element of the covariance matrix is a function of one or more model parameters.

MIMIC model is a wider model than most other models undertaken to estimate sizes of the informal economy, also flexible to allow one to vary the choice of causal and indicator variables under the particular features of the shadow economic activity. MIMIC models lead to formal estimation and testing procedures, such as those based on the method of maximum likelihood (Schneider \& Buehn, 2017). Although some studies argue on the MIMIC model do not need restrictive assumptions to operate and only real constraint of the model lies not in its conceptual structure, but the choice of variables (Schneider \& Buehn, 2017). The other limitations of the model use the observable variables simultaneously as indicators and causes in a particular study.

\section{RESULT AND DISCUSSIONS}

\section{Descriptive statistics of the study}

The causal variables of the study are tax burden, regulation, corruption, selfemployment, unemployment, tax morale, and agricultural sector dominances, and also indicator variables are harmfulness of shadow economy, money out- 
side the bank, real GDP per capita and total employment. The statistical outputs of the variables presented in the table below.

Table 1. Descriptive Statistics for the measurement and structured variables of the study

\begin{tabular}{|c|c|c|c|c|c|}
\hline Variables of study & Obs. & Mean & Std. Dev. & Min & Max \\
\hline \multicolumn{6}{|l|}{ Size of informal economy } \\
\hline Harmfulness of shadow economy & 384 & 2.278646 & .7283604 & 1 & 5 \\
\hline Money outside of bank & 384 & 4.411458 & .4927399 & 4 & 5 \\
\hline Real GDP per capita & 384 & 1.856771 & .4658645 & 1 & 5 \\
\hline Total employment & 384 & 4.447917 & .5234908 & 3 & 5 \\
\hline Tax burden & 384 & 4.200521 & .7809078 & 2 & 5 \\
\hline Regulation & 384 & 4.182292 & .7803721 & 1 & 5 \\
\hline Corruptions & 384 & 4.458333 & .7771766 & 1 & 5 \\
\hline Self-employment & 384 & 3.914063 & .8336338 & 1 & 5 \\
\hline Unemployment rate & 384 & 3.9375 & .5019544 & 2 & 5 \\
\hline Size of agricultural sectors & 384 & 3.778646 & 1.140502 & 1 & 5 \\
\hline Tax morale & 384 & 3.846354 & .7161598 & 1 & 5 \\
\hline
\end{tabular}

S o u r c e : survey data, 2019.

The above table presents the statistical summaries of the study variables to undertaken the informal economy size estimations. Per the statistical output of the indicator and causal variables of the study interpreted as follows; the harmfulness of shadow economy, money outside banks, real GDP per capita and total employments their expected values range from 2.279 to 4.448 , and these values show that the respondents' responses on the variables varying from disagreeing to agree of the measurement scales. Whereas the tax burden, regulation burdens, corruption, self-employment, unemployment rate, agricultural sectors, and tax morale the expected values range from 3.779 to 4.458 . The results imply that the respondents' responses deviated on agreeing response of the measurement scales of the informal economy. 


\section{MIMIC Models Estimation Results}

\section{Evaluating MIMIC Model Fit}

Evaluating model fit is the most controversial issue in the structural equation modeling in literature Kline (2010); Doğan and Özdamar (2017). While several attempts to obtain the rules of thumps for the assessment of the structural equation model, actually, in the present literature there is no consensus on fit indices of the structural equation modeling which show an acceptable fit (Davcik, 2014). After the structural equation model analysis was conducted, the need to take important steps for the assessment of the model. At first, the data is assessed if it fits with a prior model. After the overall model fit, individual parameters are assessed. To assess the overall model fit, use several goodness-of-fit indices to justify the model fit. The most commonly used fit index is chi-square statistics which is not recommended for the large sample size (Karakaya-Ozyer \& Aksu-Dunya, 2018). The other common fit indices are Goodness Fit Index (GFI), Comparative Fit Index (CFI), Tucker-Lewis index (TLI), Root Mean Square Error of Approximation (RMSEA), Standardized Root Mean Residual (SRMR), Akaike's information criterion (AIC) and Bayesian information criterion (BIC) (Karakaya-Ozyer \& Aksu-Dunya, 2018). Most of the time uses several types of fit indices categorized as absolute fit indices, relative fit indices, parsimony fit indices, and non-centrality based indices Kenny and McCoach (2003); Hennessy and Greenberg (1999); Smith and McMillan (2001). Per Usp and Winter (2012), categorized the model fit tests as absolute fit indices ( $\chi^{2}, \mathrm{GFI}, \mathrm{RMR}, \mathrm{SRMR}, \chi^{2} / \mathrm{df}$ ratio) and also the relative fit indices and the non-centrality based indices (CFI, TLI, RMSEA). In the below table summarizes some of the commonly used fit indices and acceptable ranges obtained from the empirical literature.

Table 2. MIMIC Model Fit and Test Statistics

\begin{tabular}{|l|c|c|}
\hline \multicolumn{1}{|c|}{ Fit Indices } & Calculated rates & Acceptable ranges \\
\hline \hline Chi-square $\left(\chi^{2}\right)$ & Not significant & P $>0.05$ \\
\hline Ratio of $\chi^{2} / d f$ & 2 & $\leq 2$ or 3 \\
\hline $\begin{array}{l}\text { Standardized Root Mean-square Residual } \\
\text { (SRMR) }\end{array}$ & 0.038 & $\begin{array}{c}<0.10 \text { favorable } \\
<0.05 \text { good }\end{array}$ \\
\hline
\end{tabular}


Table 2. MIMIC...

\begin{tabular}{|l|c|c|}
\hline \hline \multicolumn{1}{|c|}{ Fit Indices } & Calculated rates & Acceptable ranges \\
\hline \hline Goodness-of-Fit (GFI) & 0.923 & $>0.90$ good fit \\
\hline Comparative Fit Index (CFI) & 0.943 & $>0.90$ good fit \\
\hline Tucker-Lewis index(TLI) & 0.916 & $>0.90$ good fit \\
\hline $\begin{array}{l}\text { Root Mean-Square Error } \\
\text { of Approximation (RMSEA) }\end{array}$ & 0.047 & $\begin{array}{l}<0.05 \text { close } \\
<0.08 \text { good } \\
<0.10 \text { reasonable }\end{array}$ \\
\hline Akaike's information criterion(AIC) & 8077.868 & No defined level \\
\hline Bayesian information criterion(BIC) & 8152.930 & No defined level \\
\hline AIC null & 27598.90 & \\
\hline Degree of freedom(df) & 23 & \\
\hline \hline
\end{tabular}

S o u r c e : output of the MIMIC Model.

Each test of the MIMIC model from the above table indicates that the test fits the model of goodness fit to the data. In the model the RMSEA statistic is less than 0.05 (and in several cases, the 95\% confidence interval for the RMSEA includes 0.05 indicating a close fit). The other absolute fit statistics are above the cut-off points for a good fit. The sizes of an informal economy have four indicators, namely the harmfulness of shadow economy, money outside of banks and real GDP per capita. Per the above table lists of the model tests the RMSEA $=0.047<0.05, \mathrm{SRMR}=0.038<0.05, \mathrm{GFI}=0.923>0.90 ; \mathrm{CFI}=0.943>0.90 ;$ TLI $=0.916>0.9$ and also the ratio of chi-square to degree of freedom would be less than or equal to 2 and concluded that it was a very good approximation to the data. The MIMIC model fit statistics for the comparison which are below the null model values of the cut-off points (that is, for the sizes of an informal economy, $\mathrm{AIC}=8077.868$ and $\mathrm{BIC}=8152.930<$ null 27598.9).

\section{Estimation of model coefficient}

This study uses the stata14.0 to estimate the coefficients of the parameters by the maximum likelihood estimation method. The maximum likelihood estimations knowingly applicable to addresses most of the study problems, strong intuitive appeal and usually yields reasonable to the estimated coefficients of the 
study variables. The coefficients (to) be directly compared and the weight of each once explain the dynamics of the informal economy. As shown in the below figure, the MIMIC model took seven causes, a single latent variable and four indicators variables addressed in the study.

Figure 2. Hypothesized Structure of the Structural Equation Model (MIMIC Model)

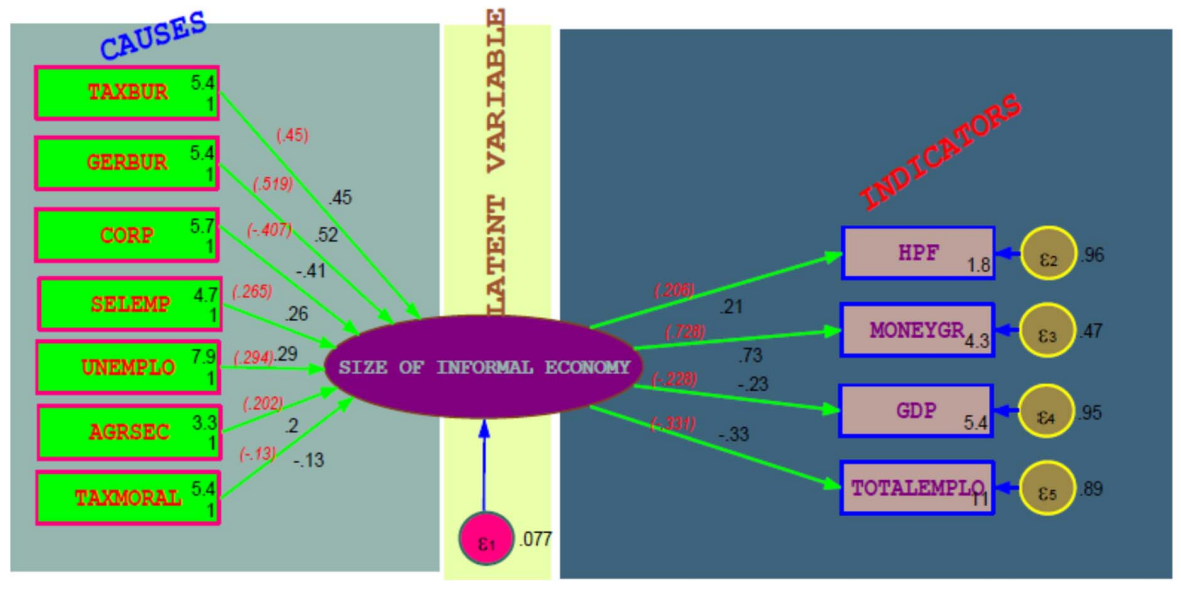

S o u r c e : author's Survey data, 2019.

The above figure shows the model outputs, signs of the casual and indicator variables. The variables hold positive and negative signs as expected from the empirical works of literature and studies of the informal economy. On this basis, the harmfulness of shadow economy (HPF), money outside banks (MONEYG), tax burdens (TAXBUR), the intensity of government regulations (GERBUR), self-employment (SELEMP), unemployment rate (UNEMPLO) and agricultural sector size (AGRSEC) have a positive effect on the size of the informal economy estimations. This implies that the increase in these variables would push more agents to join the informal business sectors and also the real GDP per capita, total employment (TOTALEMPLO), Corruption or institutional quality (CORP) and tax morale (TAXMORAL) hurt the size of the informal economy estimations; implies that the increase on these variables declined on the sizes of informal economy activities. 
In general, the model results summarize as per the econometrics analysis of the outputs, concluded that the causal variables behave as expected based on the theoretical considerations of all the variables have significant causes and indicators for the determinants of the informal economy size estimations (i.e., p-value $<0.05$ ).

Table 3. Output of Standardized Coefficients for Hypothesized Model

\begin{tabular}{|c|c|c|c|}
\hline Variables/specifications & Unstandardized & Standardized & $\mathbf{R}^{2}$ \\
\hline \multicolumn{4}{|l|}{ Causes } \\
\hline Taxes burden & $\begin{array}{l}0.086 \\
(3.64)\end{array}$ & $\begin{array}{c}0.450 * \\
(8.99)\end{array}$ & \\
\hline Government Regulations burden & $\begin{array}{l}0.100 \\
(3.64)\end{array}$ & $\begin{array}{c}0.519 * \\
(8.84)\end{array}$ & \\
\hline Institutional quality or corruption & $\begin{array}{l}-0.079 \\
(3.40)\end{array}$ & $\begin{array}{c}-0.407^{*} \\
(7.22)\end{array}$ & \\
\hline Self-employment & $\begin{array}{l}0.048 \\
(3.20)\end{array}$ & $\begin{array}{c}0.265^{*} \\
(5.13)\end{array}$ & \\
\hline Unemployment rate & $\begin{array}{l}0.088 \\
(3.46)\end{array}$ & $\begin{array}{l}0.294^{*} \\
(5.86)\end{array}$ & \\
\hline Size of Agricultural sectors & $\begin{array}{l}0.026 \\
(2.87)\end{array}$ & $\begin{array}{l}0.202^{*} \\
(4.09)\end{array}$ & \\
\hline Tax morale & $\begin{array}{l}-0.027 \\
(2.09)\end{array}$ & $\begin{array}{c}-0.130 * * \\
(2.45)\end{array}$ & \\
\hline \multicolumn{4}{|l|}{ Indicators } \\
\hline Harmfulness of shadow economy & 1 & $\begin{array}{c}0.206 * * \\
(3.93)\end{array}$ & $.042 * * *$ \\
\hline Money outside banks & $\begin{array}{l}2.393 \\
(3.87)\end{array}$ & $\begin{array}{c}0.728 * * \\
(16.18)\end{array}$ & $.530 * * *$ \\
\hline Real GDP per capita & $\begin{array}{c}-0.708 \\
(2.89)\end{array}$ & $\begin{array}{c}-0.228^{* *} \\
(4.52)\end{array}$ & $.052^{* * *}$ \\
\hline Total employment & $\begin{array}{l}-1.157 \\
(3.37)\end{array}$ & $\begin{array}{c}-0.331^{* *} \\
(6.74)\end{array}$ & $.110 * * *$ \\
\hline Size of informal economy & & & $.923 * * *$ \\
\hline
\end{tabular}

$\mathrm{N}$ o t e : Absolute z-statistics are reported in parenthesis. ${ }^{*},{ }^{* *}$ denote significance at 1 and $5 \%$ significance levels and ${ }^{* * *}$ denotes the measurement equations level $\mathrm{R}^{2}$.

S o u r c e : author's survey data, 2019. 


\section{Discussion}

The sample size and plausibility of the normality and independence assumptions needed to consider in the selection of the appropriate estimation techniques in the structural equation modeling. Inline to the maximum likelihood estimation methods for the conducted study determined the parameters of the model. The sample size of the study would be taken as 384 observations to undertake the study. Per the MIMIC model output, the log-likelihood of the model equal to -4019.9341 . In the model, regressions conducted by taking the size of the informal economy as the latent variable, the causes as the observed exogenous variables and also the indicators as the observed endogenous variables.

The MIMIC model fits adequately under the model evaluation as stated in the above table. Further to show this explanation the researchers usually examine the statistically significant relations within the model. Table 3 contains the edited Stata output for the evaluation of the regression coefficients of the parameters. Suppose the standardized parameter estimates are divided by their respective standard errors would be manipulated in manual and made the comparisons with the regression output of $\mathrm{z}$ scores would guide as to reject the null hypothesis and to accept the research hypothesis. In this study, the situations would be meets for all the variables of the model under the study. Typically this is evaluated against a $\mathrm{z}$ score associated with $\mathrm{p}<.05, \mathrm{z}=1.96$. All of the measured variables that hypothesized as predictors are significantly associated with their respective factors.

Under this study, the coefficients of the parameters, variance, and co-variance would be standardized to overcome the problems of the unstandardized coefficients difficulty for the interpretations. In the unstandardized variables are measured on different scales; therefore, researchers often examine standardized coefficients. The standardized and unstandardized regression coefficients for the final model presented in the table 3 and figure 2 . As observed from figure 2 the standardized coefficients of the study variables are presented in the parentheses. The unstandardized and standardized coefficients are given in table 3 just for comparative purposes. Following each standardized equation is an $\mathrm{R}^{2}$ value also presented in table 3 for the measurement equations. The covariance and the correlation are the same value because the variance of both latent variables was fixed into 1 . 
As listed from the above table, the responsible factors for the origin and expansion of the informal economy are taxes burden, regulations, self-employment, unemployment rate, and agricultural importance, harmfulness of shadow economy, money outside banks, real GDP per capita and total employments. For the causal variables find across all specifications in the above table taxes burden, regulations, institutional quality, self-employment, unemployment rate, agricultural importance, and tax morality are statistically significant and consistently estimated. As one standard deviation increase in the taxes burden, regulations, self-employment, unemployment rate, and agricultural importance leads to increases in the size of informal economy activity with 0.450 , $0.519,0.265,0.294$, and 0.202 units respectively. For a one standard deviation increase in the institutional quality and tax morale lead to decreases in an informal economy activity with 0.407 and 0.13 units respectively. In addition to causal variables also for the indictor variables finds across all specifications in the above table the harmfulness of shadow economy, money outside banks, real GDP per capita and total employments are statistically significant. As one standard deviation increase in the harmfulness of shadow economy and money outside banks leads to increases in the size of informal economy activity with 0.206 and 0.728 units respectively. For a one standard deviation increase in the real GDP per capita and total employment lead to decreases in an informal economy activity with 0.228 and 0.331 units respectively.

Under the MIMIC model, analysis results show that variables statistically significant to determine the sizes of an informal economy; and also determinants to estimates the size of an informal economy as well as the factors for the development of an informal economy in the developing country. Most of the scholars indicated in their study the main causes that affect the growths of the informal economy are tax and social security burden, regulations, self-employment, unemployment rates, and agricultural sector expansions. Normally, taxes affect the choice of work time since the greater the difference between the total costs of labor in the official economy and the after-tax earnings, the greater the incentive to avoid this difference and to work on the informal economy. An increase in the intensity of regulation, such as trade barriers and labor restrictions, reduces the freedom for individuals engaged in the official economy and leads to a significant increase in labor costs in the official economy.

The unemployment rate and hours of work by a worker in the formal or official economy also affect the informal economy. While it is clear that a reduction 
in working hours in the official economy increase hours worked in the shadow economy, the impact of unemployment in the informal economy is unclear. Institutional quality has a strong bearing on the competitiveness and growth of the informal economy. A weak judiciary system, excessive bureaucracy, lack of transparency, and directed credit to connected borrowers and strategic enterprises aggravate the incentives to informality. Furthermore, the stronger the enforcement capability and quality of government are, the lower the expected size of the informal economy.

\section{CONCLUSION AND RECOMMENDATIONS}

Per the MIMIC model, the hypotheses have been confirmed with their signs as stated initially in the empirical studies of the shadow economy. All the causal and indicator variables would be the determinants to estimate the size of the informal economy under the model outputs as evidenced by the sampled informal economy. While this phenomenon would be applicable in most of the developing countries' informal business sectors; the recent period studies support the results especially the studies of the Sub-Saharan African countries.

The determinants of informal economy size estimation in Ethiopia cover the tax burden, regulations, institutional quality, self-employment, unemployment rate, agricultural importance, and tax morality taken as causes whereas the harmfulness of shadow economy, money outside banks, real GDP per capita and total employment as indicators. The variables are statistically significant in the informal economy size estimation. Also, holds the positive and negative signs to show the direction on the size of informal economy estimation.

Knowingly avoiding the informal economy from the economic systems is a difficult and challenging task for the governments of the nations. The informal business sectors bring economic opportunities for the government to mobilizes the internal revenue even though requires government commitment and technology to improve the system. Finally, recommended for future scholars to undertake the study on the estimation of the size of the informal economy with the indirect approach using panel data to draw a deeper understanding on the dynamics of the informal economy and to investigate the effects of the informal economy on the regular economy. 


\section{DEFERENCES}

Alm, J., Martinez-Vazquez, J., \& Schneider, F. (2004). "Sizing" the Problem of the Hard -to-Tax. Contributions to Economic Analysis, 286, 11-75.

Andersen, E.A., \& Andersen, E.A. (2019). The shadow economy. An Ethnic Perspective on Economic Reform, 330-333. https://dx.doi.org/10.4324/9780429460098-25.

Cassel, D., \& Cichy, U. (1986). Explaining the growing shadow economy in East and West: A comparative systems approach. Comparative Economic Studies, 28(1), 20-41.

Davcik, N.S. (2014). The use and misuse of structural equation modeling in management research: A review and critique. Journal of Advances in Management Research, 11(1), 47-81. https://dx.doi.org/10.1108/JAMR-07-2013-0043.

Dilnot, A., \& Morris, C. N. (1981). What do we know about the black economy? Fiscal Studies, 2(1), 58-73. https://dx.doi.org/10.1111/j.1475-5890.1981.tb00457.x.

Doğan, İ., \& Özdamar, K. (2017). The effect of different data structures, sample sizes on model fit measures. Communications in Statistics-Simulation and Computation, 46(9), 7525-7533. https://dx.doi.org/10.1080/03610918.2016.1241409.

Eilat, Y., \& Zinnes, C. (2000). The evolution of the shadow economy in transition countries: consequences for economic growth and donor assistance. Harvard Institute for International Development, CAER II Discussion Paper, 83.

Feige, E.L. (2016). Reflections on the Meaning and Measurement of Unobserved Economies: What Do We Really Know About the "Shadow Economy". Journal of Tax Administration, 2(1), 5-41.

Feld, L.P., \& Schneider, F. (2010). Survey on the shadow economy and undeclared earnings in OECD countries. German Economic Review, 11(2), 109-149. https://dx.doi. org/10.1558/jsrnc.v4il.24.

Ferman, P.R., \& Ferman, L.A. (1973). The structural underpinnings of the irregular economy. Asia Pacific Journal of Human Resources, 8(1), 1-17. https://dx.doi. org/10.1177/103841117300800101.

Frey, B.S., Weck, H., \& Pommerehne, W.W. (1982). Has the shadow economy grown in Germany? An exploratory study. Weltwirtschaftliches Archiv, 118(3), 499-524.

Gutmann, P.M. (1977). The subterranean economy. Financial Analysts Journal, 33(6), 26-27. https://dx.doi.org/10.2469/faj.v33.n6.26.

Hennessy, M., \& Greenberg, J. (1999). Bringing it all together: Modeling intervention processes using structural equation modeling. American Journal of Evaluation, 20(3), 471-480. https://dx.doi.org/10.1177/109821409902000306.

Igudia, E., Ackrill, R., Coleman, S., \& Dobson, C. (2016). Determinants of the informal economy of an emerging economy: a multiple indicator, multiple causes approach. International Journal of Entrepreneurship and Small Business, 28(2/3), 154-177. https://dx.doi.org/10.1504/ijesb.2016.076643.

Karakaya-Ozyer, K., \& Aksu-Dunya, B. (2018). A Review of Structural Equation Modeling Applications in Turkish Educational Science Literature, 2010-2015. International Journal of Research in Education and Science, 4(1), 279-291. https://dx.doi. org/10.21890/ijres.383177. 
Kenny, D.A., \& McCoach, D.B. (2003). Effect of the number of variables on measures of fit in structural equation modeling. Structural Equation Modeling, 10(3), 333-351. https://dx.doi.org/10.1207/S15328007SEM1003_1.

Kline, R.B. (2010). Promise and pitfalls of structural equation modeling in gifted research. In B. Thompson, R.F. Subotnik (Eds.). Methodologies for conducting research on giftedness. Washington: American Psychological Association. https://dx.doi. org/10.1037/12079-007.

Leite, C., \& Master, S. (2014). Shadow Economy in Portugal: computation by different approaches. Porto: FEP Economics and Management University of Porto.

McCrohan, K., Smith, J.D., \& Adams, T.K. (1991). Consumer purchases in informal markets: estimates for the 1980s, prospects for the 1990s. Journal of Retailing, 67(1), 22-50.

McCrohan, K.F., \& Smith, J.D. (1987). Consumer participation in the informal economy. Journal of the Academy of Marketing Science, 15(4), 62-68. https://dx.doi. org/10.1007/BF02723291.

Öğ̈̈nç, F., \& Yılmaz, G. (2000). Estimating the underground economy in Turkey. CBRT Research Department Discussion Paper.

Pesut, M. (1992). Statistics of the hidden economy and informal activities inside the production boundary of the national accounts. An overview of national practices. Statistical Journal of the United Nations Economic Commission for Europe, 9(1), 1-26. https://dx.doi.org/10.20595/jjbf.19.0_3.

Quintin, E. (2014). The Informal Sector in Developing Countries: Output, Assets and Employment. Washington: World Institute for Development Economic Research. https://dx.doi.org/10.1093/acprof:oso/9780199548880.003.0018.

Rafael, G., \& Castro, B. (2018). The Informal Economy and Its Impact on Tax Revenues and Economic Growth. Analysis of OCDE members and Latin America Countries (1995-2016), 0-54.

Sancak, C., Devine, H., Cangul, M., Wu, F., Liu, Y., Nose, M., \& Thomas, A. (2017). 3. The Informal Economy in Sub-Saharan Africa. Washington: Regional Economic Outlook, International Monetary Fund.

Schneider, F., \& Buehn, A. (2016). Estimating the Size of the Shadow Economy: Methods, Problems and Open Questions. IZA Discussion Paper, 9820.

Schneider, F., \& Enste, D. (2002). Hiding in the shadows: the growth of the underground economy. International Monetary Fund, 30.

Schneider, F. (2003). The size and development of the shadow economies and shadow economy labor force of 22 transition and 21 OECD countries: what do we really know? The informal economy in the EU access countries: Size, scope, trends and challenges to the process of EU enlar. Center for Study of Democracy, 23-61.

Schneider, F. (2014). The shadow economy: an essay. Linz: Johannes Kepler University of Linz.

Schneider, F. (2015). Size and Development of the Shadow Economy of 31 European and 5 other OECD Countries from 2003 to 2014: Different Developments? Journal of SelfGovernance and Management Economics, 3(4), 7-29. https://repositorio.unan.edu. ni/2986/1/5624.pdf (accessed: 12.12.2019). 
Schneider, F., \& Buehn, A. (2017). Shadow Economy: Estimation Methods, Problems, Results and Open questions. Open Economics, 1(1), 1-29. https://dx.doi.org/10.1515/ openec-2017-0001.

Singh, A., \& Masuku, M. (2014). Sampling Techniques \& Determination of Sample Size in Applied Statistics Research: an Overview. Ijecm.Co.Uk, II(11), 1-22. http://ijecm. co.uk/wp-content/uploads/2014/11/21131.pdf (accessed: 6.12.2019).

Sison, C.P., \& Glaz, J. (1995). Simultaneous confidence intervals and sample size determination for multinomial proportions. Journal of the American Statistical Association, 90(429), 366-369.

Smith, T.D., \& McMillan, B.F. (2001). A Primer of Model Fit Indices in Structural Equation Modeling. New Orleans: Southwest Educational Research Association.

Trebicka, B. (2014). Mimic Model: A Tool to Estimate the Shadow Economy. Academic Journal of Interdisciplinary Studies, 3(6), 295-300. https://dx.doi.org/10.5901/ ajis.2014.v3n6p295.

Usp, N., \& Winter, S.E.M. (2012). Some Clarifications and Recommendations on Fit Indices. Structural Equation Modeling, 523/623, 1-4.

Williams, C.C., \& Schneider, F. (2013). The shadow economy. London: Institute of Economic Affairs. 


\title{
APPENDIX: ECONOMETRICS MODEL OUT
}

\author{
Endogenous variables \\ Measurement: HPF MONEYGR GDP TOTALEMPLO \\ Latent: Sizeinformaleconomy \\ Exogenous variables \\ Observed: TAXBUR GERBUR CORP SELEMP UNEMPLO AGRSEC TAXMORAL
}

Fitting target model:

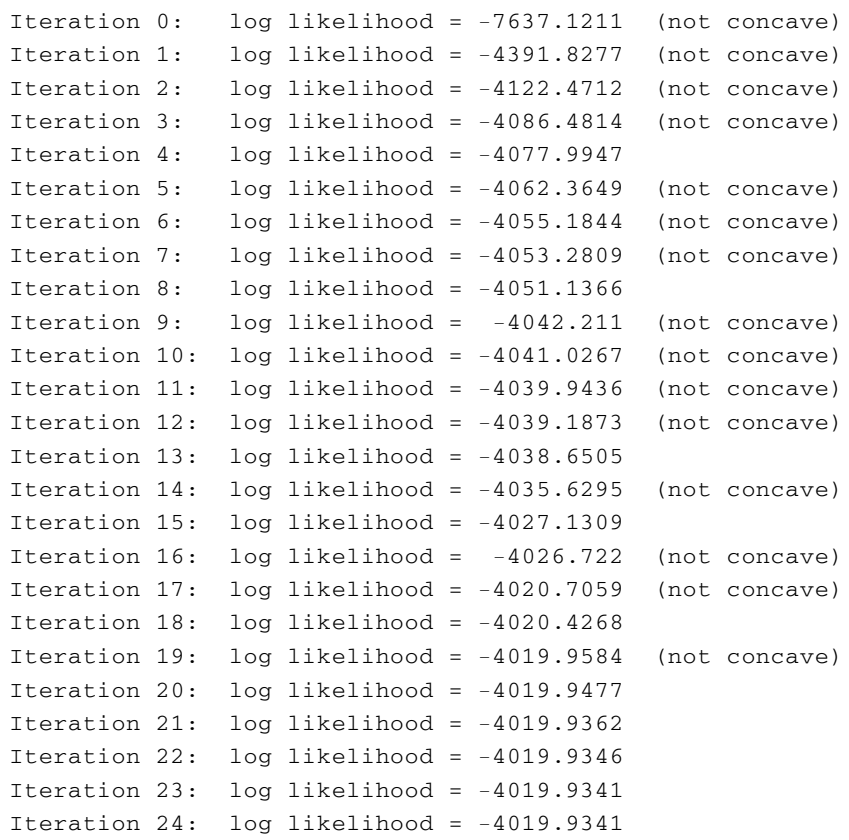

(1) [HPF] Sizeinformaleconomy $=1$ 


\begin{tabular}{|c|c|c|c|c|c|c|}
\hline \multirow{2}{*}{ Standardized } & \multicolumn{3}{|c|}{ OIM } & \multirow[b]{2}{*}{$P>|z|$} & \multirow[b]{2}{*}{$95 \%$ Conf. } & \multirow[b]{2}{*}{ Interval] } \\
\hline & Coef. & Sta. Err. & $\mathrm{z}$ & & & \\
\hline \multicolumn{7}{|l|}{ Structural } \\
\hline \multicolumn{7}{|l|}{ Sizeinformaleconomy <- } \\
\hline TAXBUR & .4499064 & .05007 & 8.99 & 0.000 & .3517711 & .5480418 \\
\hline GERBUR & .5189171 & .0586832 & 8.84 & 0.000 & .4039 & .6339341 \\
\hline CORP & -.4071797 & .0563836 & -7.22 & 0.000 & -.5176895 & -.29667 \\
\hline SELEMP & .2645258 & .0515961 & 5.13 & 0.000 & .1633994 & .3656523 \\
\hline UNEMPLO & .2942483 & .0502406 & 5.86 & 0.000 & .1957786 & .392718 \\
\hline AGRSEC & .2015582 & .0493226 & 4.09 & 0.000 & .1048877 & .2982287 \\
\hline TAXMORAL & -.1298906 & .0530535 & -2.45 & 0.014 & -.2338735 & -.0259077 \\
\hline \multicolumn{7}{|l|}{ Measurement } \\
\hline \multicolumn{7}{|l|}{ HPF $<-$} \\
\hline Sizeinformaleconomy & .2058418 & .0523612 & 3.93 & 0.000 & .1032157 & .308468 \\
\hline -cons & 1.816391 & .3672244 & 4.95 & 0.000 & 1.096644 & 2.536138 \\
\hline \multicolumn{7}{|l|}{ MONEYGR <- } \\
\hline Sizeinformaleconomy & .7280326 & .0450038 & 16.18 & 0.000 & .6398267 & .8162385 \\
\hline _cons & 4.309564 & .5294842 & 8.14 & 0.000 & 3.271794 & 5.347334 \\
\hline \multicolumn{7}{|l|}{ GDP $<-$} \\
\hline Sizeinformaleconomy & -.2278497 & .0503766 & -4.52 & 0.000 & -.3265861 & -.1291134 \\
\hline - cons & 5.447714 & .3589089 & 15.18 & 0.000 & 4.744265 & 6.151162 \\
\hline \multicolumn{7}{|l|}{ TOTALEMPLO <- } \\
\hline Sizeinformaleconomy & -.3313506 & .049194 & -6.74 & 0.000 & -.427769 & -.2349322 \\
\hline _cons & 10.62638 & .4304112 & 24.69 & 0.000 & 9.782793 & 11.46997 \\
\hline $\operatorname{var}(e \cdot H P F)$ & .9576291 & .0215563 & & & .9162981 & 1.000825 \\
\hline $\operatorname{var}($ e.MONEYGR) & .4699685 & .0655285 & & & .3575891 & .6176654 \\
\hline $\operatorname{var}(e \cdot G D P)$ & .9480845 & .0229566 & & & .9041414 & .9941633 \\
\hline $\operatorname{var}($ e.TOTALEMPLO) & .8902068 & .0326009 & & & .8285494 & .9564524 \\
\hline var (e.Sizeinformaleconomy) & .0765711 & .0998446 & & & .0059449 & .9862491 \\
\hline
\end{tabular}

LR test of model vs. saturated: $\operatorname{chi2}(23)=42.38$, Prob $>$ chi2 $=0.0082$

S o u r c e : author's Survey data, 2019 output. 